\title{
Linagliptin and cardiovascular outcomes in type 2 diabetes after acute coronary syndrome or acute ischemic stroke
}

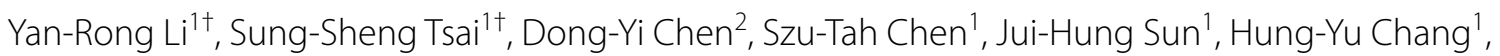 \\ Miaw-Jene Liou' ${ }^{1}$ and Tien-Hsing Chen ${ }^{3,4^{*}}$
}

\begin{abstract}
Background: The cardiovascular safety and efficacy of linagliptin, a dipeptidyl peptidase-4 inhibitor, in patients with type 2 diabetes mellitus (T2DM) after acute coronary syndrome (ACS) or acute ischemic stroke (AIS) are unclear. The aim of our real-world cohort study was to evaluate the cardiovascular outcomes of linagliptin in patients with T2DM after ACS or AIS.

Methods: An open observational noncrossover retrospective cohort study was conducted between June 1, 2012 and December 31, 2013 utilizing Taiwan National Health Insurance Research Database. A total of 1203 patients with T2DM after ACS or AIS were selected as the study cohort. Cardiovascular safety and efficacy of linagliptin were evaluated by comparing outcomes of 401 subjects receiving linagliptin after ACS or AIS to 802 matched control subjects not receiving any incretin-based therapy after ACS or AIS. The primary composite outcome included cardiovascular death, non-fatal myocardial infarction and non-fatal ischemic stroke.
\end{abstract}

Results: The primary composite outcome after 15-month follow-up was 7\% (28 patients) in the linagliptin group compared with 6.1\% (49 patients) in the control group [hazard ratio (HR) 1.06; 95\% confidence interval (CI) .66-1.68]. The linagliptin group also had similar risks of all-cause mortality, hospitalization for heart failure, percutaneous coronary intervention and coronary artery bypass grafting compared to the control group in terms of the secondary outcomes.

Conclusions: In T2DM patients after ACS or AIS, treatment with linagliptin was not associated with increased risks of cardiovascular death, non-fatal myocardial infarction, or non-fatal ischemic stroke.

Keywords: Linagliptin, Dipeptidyl peptidase-4 (DPP-4) inhibitor, Type 2 diabetes mellitus, Acute coronary syndrome, Acute ischemic stroke, Cardiovascular outcome

\section{Background}

Type 2 diabetes mellitus (T2DM) is considered as an equivalent of coronary heart disease [1] with a twofold higher risk both for ischemic stroke [2] and mortality [3] compared to those without T2DM. More than 50\% of deaths in diabetic patients were attributed to cardiovascular complications [4]. Although improvement

\footnotetext{
*Correspondence: skyheart0826@gmail.com

${ }^{\dagger}$ Yan-Rong Li and Sung-Sheng Tsai contributed equally as first author

${ }^{3}$ Division of Cardiology, Department of Internal Medicine, Chang Gung

Memorial Hospital, No.222, Maijin Road, Keelung, Taiwan

Full list of author information is available at the end of the article
}

of glycemic control reduces the risk of microvascular complications in patients with T2DM [5], several clinical trials have shown no benefit of reducing macrovascular risks with intensively glycemic control, especially for T2DM patients at high risk for cardiovascular events [6-9]. Another issue of concern raised by the Food and Drug Administration (FDA) in December 2008 is that the anti-diabetic agents should not be attributed to increase adverse events of cardiovascular diseases [10]; thus, specific requirements for cardiovascular safety assessment before and after the approval must be met [11]. 
Four kinds of dipeptidyl peptidase-4 (DPP-4) inhibitors (saxagliptin, alogliptin, sitagliptin, and linagliptin) are available for the treatment of T2DM in the United States. Vildagliptin is approved for use in many countries but not in the United States. Among them, three previous cardiovascular outcome trials of DPP-4 inhibitors (Saxagliptin Assessment of Vascular Outcomes Recorded in Patients with Diabetes Mellitus-Thrombolysis in Myocardial Infarction 53 (SAVOR-TIMI 53), Examination of Cardiovascular Outcomes With Alogliptin Versus Standard of Care (EXAMINE), Trial Evaluating Cardiovascular Outcomes with Sitagliptin (TECOS)) suggested no increased risks of cardiovascular death, myocardial infarction and stroke with a short-term use (a median follow-up of 1.5-3 years) of DPP-4 inhibitors [12-14], but an increased risk of heart failure with specific DPP-4 inhibitors were observed [12, 15]. The FDA on April 5, 2016 recommended the discontinuation of the use of saxagliptin or alogliptin in patients with T2DM if there is any evidence of emerging heart failure [16]. As a result, it seems to be not a class effect of DPP-4 inhibitors in the view of increasing heart failure [17].

Linagliptin exerts anti-hyperglycemic effects by increasing and prolonging active glucagon-like peptide-1 (GLP-1) levels which leads to increase pancreatic insulin secretion and suppressing pancreatic glucagon secretion [18]. The features of linagliptin are xanthine-based compounds which differ from the other DPP-4 inhibitors with higher selectivity for DPP-4 versus DPP-8 (40,000-fold) and DPP-9 (> 10,000-fold) $[18,19]$ and no dosage adjustment in renal insufficiency including end-stage renal disease because of primarily eliminated via the enterohepatic system [20]. Therefore, it is not clear whether the pharmacological differences between linagliptin and other DPP-4 inhibitors may result in differences in the cardiovascular safety profile. Two ongoing cardiovascular outcome trials for linagliptin (the Cardiovascular and Renal Microvascular Outcome Study with Linagliptin in Patients with Type 2 Diabetes Mellitus (CARMELINA) and the Cardiovascular Outcome Study of Linagliptin Versus Glimepiride in Patients with Type 2 Diabetes (CAROLINA)) estimate the completion of the studies by January 2018 [21] and March 2019 [22], respectively. However, one caveat to be considered in both clinical trials of CARMELINA and CAROLINA is that patients with recent acute coronary syndrome or acute stroke were excluded from these clinical studies. Therefore, there is still limited post-marketing data about safety and efficacy of linagliptin in patients at very high cardiovascular risks [23, 24]. Moreover, some evidence suggested that linagliptin may have neuroprotective effects and be associated with significantly fewer events of stroke [25, 26]. As a result, the aim of our real-world cohort study was to evaluate the cardiovascular outcomes of linagliptin T2DM patients after acute coronary syndrome (ACS) or acute ischemic stroke (AIS).

\section{Methods \\ Data source}

The National Health Insurance (NHI) program covers more than $99 \%$ of the 23 million people in Taiwan. All the submitted standardized information and data on healthcare service are prospectively recorded by the NHI Research Database (NHIRD). The diagnoses are registered using the International Classification of Diseases, Ninth Revision, Clinical Modification (ICD-9-CM) codes. The NHI Bureau routinely and comprehensively performs the validation of accurate records of beneficiaries, including ambulatory visits, inpatient care, disease diagnosis codes and medication prescriptions from the NHIRD data [27-30]. This kind of nationwide database from the NHIRD is important and contributory to many large population-based studies [31]. The personal informations and records of the patients were de-identified before analysis to ensure patients' anonymity. This study was approved by the Ethics Institutional Review Board of Chang Gung Memorial Hospital (201701079B1).

\section{Patient enrollment and exclusion criteria}

This open observational noncrossover retrospective cohort study was derived from the NHIRD. Between June 1, 2012 and December 31, 2013, a total of 1,759,222 T2DM (ICD-9-CM code: 250) patients were initially enrolled and after applying exclusion criteria, a final total of 1203 T2DM patients who were hospitalized for ACS (ICD-9-CM codes: 410-411) or AIS (ICD-9-CM codes: 433-435) were included in our study (Fig. 1). The index hospitalization was defined as the date on which patient was admitted for ACS or AIS. In addition to identifying T2DM patients using ICD-9-CM codes, we defined T2DM patients with at least 90 days of prescribed oral hypoglycemic agents or insulin injection within 1 year of the index hospitalization.

The follow-up period was based upon the index hospitalization to date of death, loss of follow-up, or until December 31, 2013. Patients' baseline characteristics, comorbidities, medication prescription and previous medical procedures, such as percutaneous coronary intervention (PCI), coronary artery bypass grafting (CABG) and carotid stenting were identified. Patients were excluded if they met any of the following criteria: (1) age below 40 years; (2) use of any DPP-4 inhibitors except for linagliptin or any glucagon-like peptide-1 receptor agonists (GLP-1 RA) before the index hospitalization; (4) use of other DPP-4 inhibitors or any GLP-1 RA after the index hospitalization; (5) expiration during index 


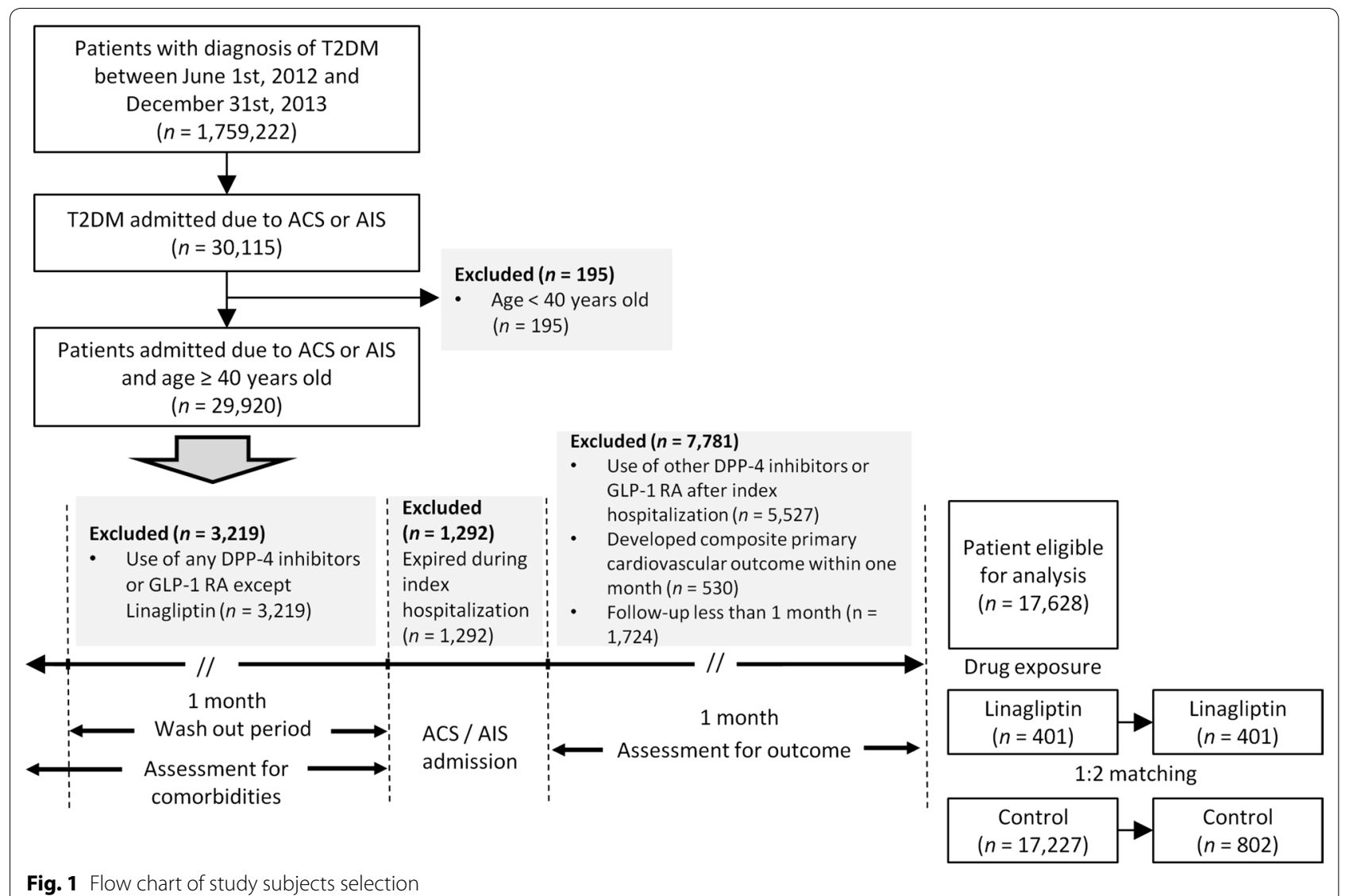

Fig. 1 Flow chart of study subjects selection

admission; (6) development of composite primary cardiovascular outcome within 1 month of index hospitalization or (7) follow-up for less than 1 month after index hospitalization. The exclusion criteria are shown in Fig. 1.

\section{Exposure of linagliptin}

In the study period, the exposure to linagliptin was based on a computer-based prescription claims after the index hospitalization. Patients with T2DM after ACS or AIS were classified into the linagliptin group or the control group in which patients did not receive incretin-based therapies (any DPP-4 inhibitors or GLP-1 RA) after ACS or AIS.

\section{Outcomes and covariate measurements}

Baseline comorbidities were identified using ICD-9-CM diagnosis codes and medications during the index hospitalization (Tables 1, 2). The primary composite outcome included cardiovascular death, non-fatal myocardial infarction and non-fatal ischemic stroke. The definition of cardiovascular death meet the criteria of Standardized Definitions for End Point Events in Cardiovascular Trials draft by the Food and Drug Administration. Death and causes of death were according to the registry data of NHIRD [32]. Secondary outcomes of interest were death due to any cause, hospitalization for heart failure, percutaneous coronary intervention and coronary artery bypass grafting. Safety outcomes were risks of hypoglycemia, diabetic ketoacidosis, hyperosmolar hyperglycemic state, acute pancreatitis, de novo dialysis, acute hepatitis or newly diagnosed malignancy.

\section{Statistical analysis}

We matched the linagliptin cohort with the control group by a 1:2 ratio based on patient's characteristics, baseline comorbidities, medication prescribed 90 days since indexed hospitalization (listed in Tables 1, 2), and index year and month by propensity score matching (PSM) to minimize potential selection bias for this cohort study. Clinical characteristics between these two study groups were compared using Chi square test for categorical variables and independent sample t test for continuous variables. Differences between these two study groups in time of the first occurrence of a predefined primary or secondary outcome after index hospitalization were determined by Cox proportional hazard models in which the study group (linagliptin group versus control group) was the only explanatory variable. Time-to-event outcomes were 
Table 1 Characteristics of the study patients before and after propensity score matching

\begin{tabular}{|c|c|c|c|c|c|}
\hline \multirow[t]{2}{*}{ Characteristics } & \multicolumn{3}{|c|}{ Before matching } & \multicolumn{2}{|c|}{ After matching } \\
\hline & $\begin{array}{l}\text { Linagliptin } \\
(n=401)\end{array}$ & $\begin{array}{l}\text { Control } \\
(n=17,227)\end{array}$ & $P$ & $\begin{array}{l}\text { Control } \\
(n=802)\end{array}$ & $P$ \\
\hline Age, years & $69.6 \pm 10.9$ & $70.0 \pm 11.1$ & .525 & $69.1 \pm 11.3$ & .415 \\
\hline Age $\geq 75$ years & $143(35.7)$ & $6216(36.1)$ & .862 & $263(32.8)$ & .321 \\
\hline Gender & & & .081 & & .744 \\
\hline Male & $216(53.9)$ & $10,029(58.2)$ & & $424(52.9)$ & \\
\hline Female & $185(46.1)$ & $7198(41.8)$ & & $378(47.1)$ & \\
\hline T2DM duration, years & $12.9 \pm 3.5$ & $11.7 \pm 3.9$ & $<.001$ & $12.8 \pm 3.4$ & .922 \\
\hline T2DM duration group (years) & & & $<.001$ & & .825 \\
\hline $0-5$ & $20(5.0)$ & $1508(8.8)$ & & $38(4.7)$ & \\
\hline $6-10$ & $54(13.5)$ & 3064 (17.8) & & $121(15.1)$ & \\
\hline $11-15$ & $212(52.9)$ & $9425(54.7)$ & & $405(50.5)$ & \\
\hline$>15$ & $115(28.7)$ & $3230(18.8)$ & & $238(29.7)$ & \\
\hline \multicolumn{6}{|l|}{ Comorbidity } \\
\hline Old myocardial infarction & $45(11.2)$ & $1524(8.8)$ & .099 & $83(10.3)$ & .643 \\
\hline Old ischemic stroke & $101(25.2)$ & $4837(28.1)$ & .203 & $229(28.6)$ & .217 \\
\hline Heart failure & $70(17.5)$ & $2467(14.3)$ & .077 & $129(16.1)$ & .546 \\
\hline Venous thromboembolism & $11(2.7)$ & $241(1.4)$ & .025 & $21(2.6)$ & .899 \\
\hline Chronic kidney disease (CKD) & & & $<.001$ & & .469 \\
\hline None & $207(51.6)$ & $11,642(67.6)$ & & $444(55.4)$ & \\
\hline Non-dialysis CKD & $161(40.2)$ & $4479(26.0)$ & & $298(37.1)$ & \\
\hline Dialysis & $33(8.2)$ & $1106(6.4)$ & & $60(7.5)$ & \\
\hline Gout & $34(8.5)$ & $1506(8.7)$ & .854 & $70(8.7)$ & .885 \\
\hline Atrial fibrillation & $35(8.7)$ & $1521(8.8)$ & .944 & $54(6.7)$ & .213 \\
\hline Peripheral arterial disease & $28(7.0)$ & $1058(6.1)$ & .489 & $59(7.4)$ & .813 \\
\hline Hypertension & $337(84.0)$ & $13,851(80.4)$ & .069 & $682(85.0)$ & .650 \\
\hline Dyslipidemia & $186(46.4)$ & $6534(37.9)$ & .001 & $350(43.6)$ & .367 \\
\hline COPD & $30(7.5)$ & $1534(8.9)$ & .322 & $63(7.9)$ & .819 \\
\hline Malignancy & $25(6.2)$ & $1269(7.4)$ & .390 & $58(7.2)$ & .520 \\
\hline Cirrhosis & $8(2.0)$ & $356(2.1)$ & .921 & $16(2.0)$ & 1.000 \\
\hline Autoimmune disease & $15(3.7)$ & $280(1.6)$ & .001 & $34(4.2)$ & .680 \\
\hline \multicolumn{6}{|l|}{ Previous treatment } \\
\hline $\mathrm{PCl}$ & $58(14.5)$ & $2110(12.2)$ & .182 & $112(14.0)$ & .815 \\
\hline CABG & $18(4.5)$ & $419(2.4)$ & .009 & $36(4.5)$ & 1.000 \\
\hline
\end{tabular}

Values are the mean \pm SD or $\mathrm{n}(\%)$

$C A B G$ coronary artery bypass grafting, COPD chronic obstructive pulmonary disease, $P C l$ percutaneous coronary intervention, $T 2 D M$ type 2 diabetes mellitus

analyzed using predefined periods, including 6 months and until the final follow-up for each study group using the Kaplan-Meier method and log-rank test. A $P$ value of less than .05 was considered statistically significant. All data analyses were performed using the SAS version 9.4 (SAS Institute, Cary, NC).

\section{Results}

\section{Study patients}

A total of 1,759,222 T2DM patients were initially enrolled between June 1, 2012 and December 31, 2013, among whom 30,115 T2DM patients were admitted for ACS or AIS. After applying the exclusion criteria, a total of
$17,628 \mathrm{~T} 2 \mathrm{DM}$ patients aged $\geq 40$ years who were hospitalized for ACS or AIS were eligible for our study cohort. After PSM was used to reduce potential confounding and selection bias, the data of 1203 patients were finally included for analyses (Fig. 1).

\section{Baseline characteristics}

Among the 1203 included patients, 401 (33.3\%) were in the linagliptin group and 802 matched patients $(66.7 \%)$ were in the control group. The mean age for the overall cohort was 69.3 years (standard deviation $[\mathrm{SD}]=11.2$ years). The mean follow-up period was 4.7 months ( $\mathrm{SD}=2.7$ months) and the maximum 
Table 2 Medications of the study patients before and after propensity score matching

\begin{tabular}{|c|c|c|c|c|c|}
\hline \multirow[t]{2}{*}{ Characteristics } & \multicolumn{3}{|l|}{ Before matching } & \multicolumn{2}{|l|}{ After matching } \\
\hline & Linagliptin $(n=401)$ & Control $(n=17,227)$ & $P$ & Control $(n=802)$ & $P$ \\
\hline \multicolumn{6}{|l|}{ Non-DM medication } \\
\hline Aspirin & $341(85.0)$ & $14,549(84.5)$ & .750 & $682(85.0)$ & 1.000 \\
\hline Clopidogrel & $206(51.4)$ & $6696(38.9)$ & $<.001$ & $393(49.0)$ & .439 \\
\hline Warfarin & $24(6.0)$ & $1096(6.4)$ & .760 & $47(5.9)$ & .931 \\
\hline NOAC & $4(1.0)$ & $197(1.1)$ & .785 & $8(1.0)$ & 1.000 \\
\hline ACEI/ARB & $275(68.6)$ & $10,829(62.9)$ & .019 & $548(68.3)$ & .930 \\
\hline$\beta$-blocker & $208(51.9)$ & $7388(42.9)$ & $<.001$ & $421(52.5)$ & .838 \\
\hline$C C B$ & $209(52.1)$ & $8963(52.0)$ & .971 & $431(53.7)$ & .595 \\
\hline Digoxin & $20(5.0)$ & $957(5.6)$ & .623 & $45(5.6)$ & .652 \\
\hline Statin & $218(54.4)$ & $8048(46.7)$ & .002 & $443(55.2)$ & .774 \\
\hline NSAID & $99(24.7)$ & $4321(25.1)$ & .857 & $208(25.9)$ & .640 \\
\hline Cox-2 inhibitor & $28(7.0)$ & $1493(8.7)$ & .235 & $54(6.7)$ & .871 \\
\hline Diuretic & $116(28.9)$ & $3528(20.5)$ & $<.001$ & $217(27.1)$ & .494 \\
\hline Spironolactone & $35(8.7)$ & $1355(7.9)$ & .526 & $65(8.1)$ & .712 \\
\hline Fibrate & $32(8.0)$ & $1242(7.2)$ & .556 & $72(9.0)$ & .562 \\
\hline \multicolumn{6}{|l|}{ DM medication } \\
\hline Biguanide & $156(38.9)$ & $8177(47.5)$ & .001 & $331(41.3)$ & .430 \\
\hline Sulfonylurea & $204(50.9)$ & $6864(39.8)$ & $<.001$ & $445(55.5)$ & .130 \\
\hline Thiazolidinedione & $27(6.7)$ & $869(5.0)$ & .128 & $47(5.9)$ & .553 \\
\hline Alpha-glucosidase inhibitor & $81(20.2)$ & $2037(11.8)$ & $<.001$ & $165(20.6)$ & .879 \\
\hline Non-SU insulin secretagogue (Glinide) & $93(23.2)$ & $2397(13.9)$ & $<.001$ & $164(20.4)$ & .274 \\
\hline Insulin & $244(60.8)$ & $7807(45.3)$ & $<.001$ & $484(60.3)$ & .868 \\
\hline
\end{tabular}

Values are the mean \pm SD or $\mathrm{n}(\%)$

$A C E I / A R B$ angiotensin-converting-enzyme inhibitor/angiotensin receptor blocker, $C C B$ calcium channel blocker, DM diabetes mellitus, NOAC novel oral anticoagulant, Non-SU non-sulfonylurea, NSAID non-steroidal anti-inflammatory drug

follow-up time was 15 months. After PSM, the two study groups were well matched in terms of baseline characteristics, comorbidities and non-study medications (Tables 1 and 2). The most common co-morbidity was hypertension ( $84 \%$ vs. $85 \%)$, followed by chronic kidney disease (48.4\% vs. $44.6 \%)$ and dyslipidemia ( $46.4 \%$ vs. $43.6 \%)$ in the linagliptin and the control groups, respectively. In addition, patients with old myocardial infarction, heart failure and old ischemic stroke in the linagliptin group were $11.2,17.5$ and $25.2 \%$, respectively; in the control group, those with old myocardial infarction, heart failure and old ischemic stroke were $10.3,16.1$ and $28.6 \%$, respectively (Table 1 ).

Based on the summary of matched nonstudy medications of anti-diabetic agents (Table 2), both groups had high prevalence of insulin use (linagliptin group: $60.8 \%$ and control group: 60.3\%), sulfonylurea use (linagliptin group: 50.9\% and control group: 55.5\%), and alpha-glucosidase inhibitors (linagliptin group: $20.2 \%$ and control group: $20.6 \%$ ).

\section{Primary outcomes}

The event-free survival curves of primary composite outcome and each component in these two study groups were plotted (Fig. 2a-d). Events of primary composite outcome occurred in 28 patients $(7 \%)$ in the linagliptin group and in 49 patients (6.1\%) in the control group (HR 1.06; 95\% CI .66-1.68) at the final follow-up (Fig. 3). With regard to the individual composite outcome, there was no significant differences in the risks of cardiovascular death (HR 1.12; 95\% CI .55-2.29), non-fatal myocardial infarction (HR 1.53; 95\% CI .64-3.70) and non-fatal ischemic stroke (HR .96; 95\% CI .45-2.07) (Fig. 3). In the subgroup analysis, there were no significant interactions in the prespecified primary cardiovascular outcomes (Fig. 4).

Tables 3 and 4 show primary outcomes in T2DM patients with ACS or AIS, respectively and reveal linagliptin had a neutral effect on cardiovascular death, nonfatal myocardial infarction and non-fatal stroke in either ACS cohort or AIS cohort. 


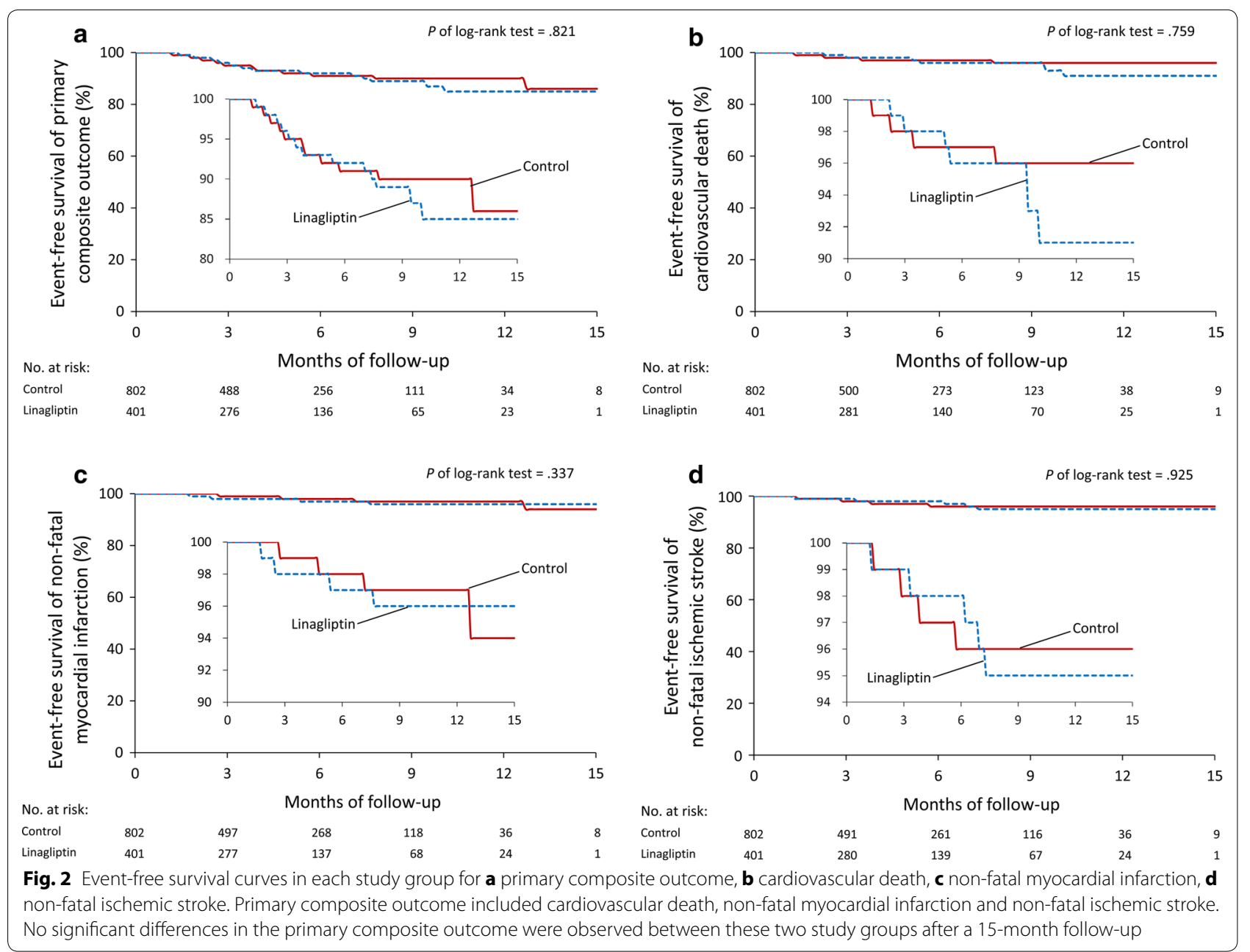

\section{Secondary outcomes}

For secondary outcomes, no significant differences occurred between the linagliptin group and the control group in the respective incidence of all-cause mortality (5.5 and 5.9\%; $P=.550$ ), hospitalization for heart failure (5.2 and $5.1 \% ; P=.964)$, percutaneous coronary intervention $(7.2$ and $4.6 \% ; P=.098)$ and coronary artery bypass grafting ( 1.0 and $.9 \% ; P=.868$ ) (Fig. 5 ). Tables 3 and 4 show secondary outcomes in T2DM patients with ACS or AIS, respectively and reveal no significant differences in either ACS cohort or AIS cohort.

\section{Safety outcomes}

The linagliptin and control groups did not differ significantly with respect to the incidences of hypoglycemia (4.2 and 3.7\%; $P=.765$ ), diabetic ketoacidosis/hyperosmolar hyperglycemic state (.7 and $1.1 \% ; P=.502$ ), acute pancreatitis ( 0 and $.4 \% ; P=$ not applicable), de novo dialysis $(4.7$ and $5.9 \% ; P=.600)$, acute hepatitis $(.5$ and $0 \%$;
$P=$ not applicable), or newly diagnosed malignancy $(2.0$ and $2.7 \%$; $P=.633$ ) (Fig. 5).

\section{Discussion}

The strength of our research is that it is the first real world and nationwide population-based study to evaluate the cardiovascular outcomes of linagliptin treatment in T2DM patients after ACS or AIS. The results of our study suggested that short-term use of linagliptin had a neutral effect on composite cardiovascular outcomes in patients with T2DM aged $\geq 40$ years after ACS or AIS who were at extremely high risks of further cardiovascular events without increasing the risks of all-cause mortality, hospitalization for heart failure, receiving percutaneous coronary intervention and coronary artery bypass grafting. For safety issues of linagliptin, two well-designed, randomized double-blinded clinical trial, CARMELINA and CAROLINA, respectively, are in progress and results are pending. Nevertheless, both trials exclude patients who suffered from a recent ACS or AIS. Therefore, another 


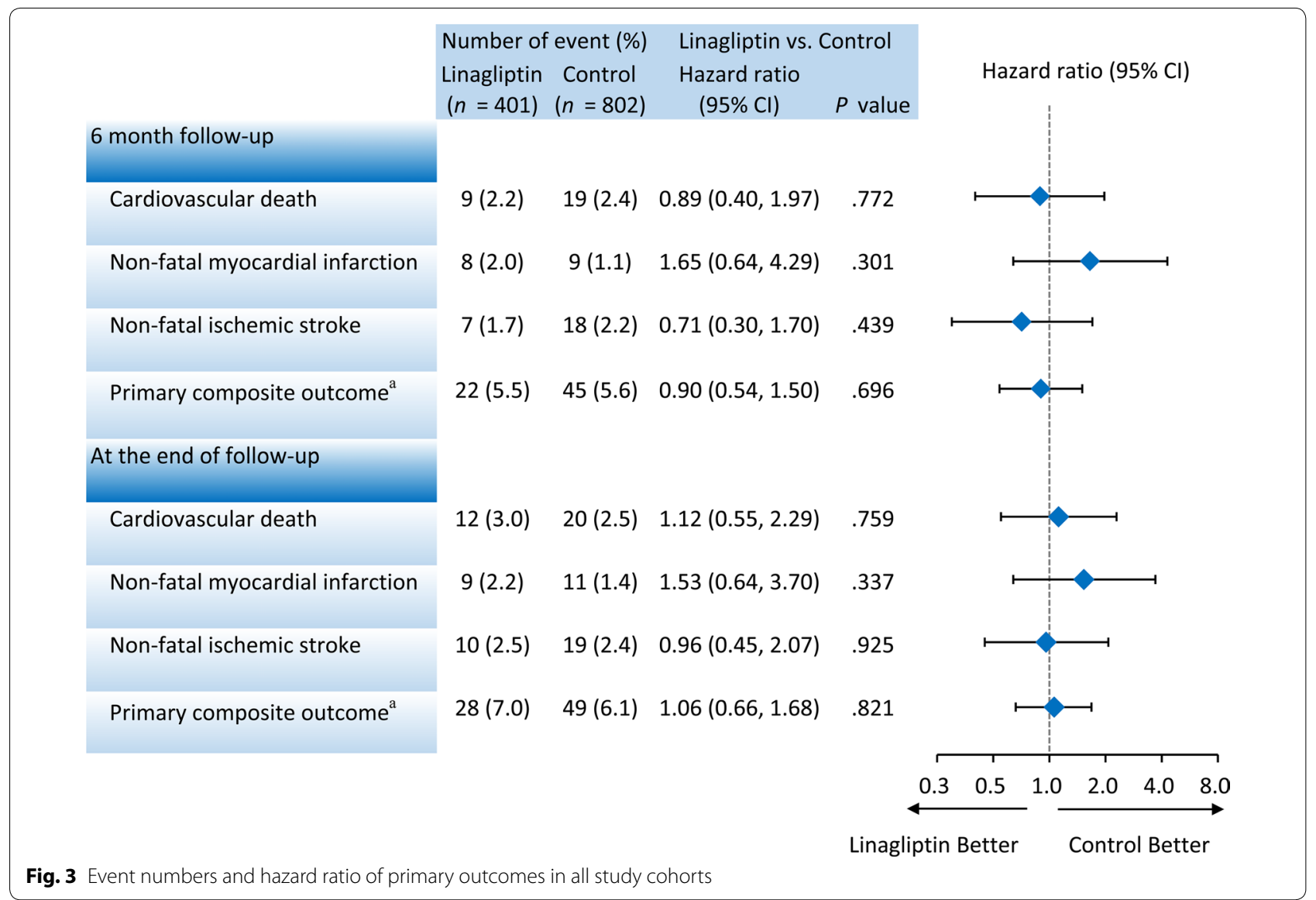

valuable strength of our research is that we filled the gap of evidence in this special population with these very high-risk patients who presumably increase the event rate of major cardiovascular diseases to complete the study in a relatively brief period.

\section{Cardiovascular end points}

Several experimental and clinical researches revealed that T2DM patients who were treated with DPP-4 inhibitors had lower risks for cardiovascular diseases as compared to those treated without DPP-4 inhibitors, except for metformin users [33], and DPP-4 inhibitors did not increase the risk of heart failure compared with sulfonylurea [34]. With regard to linagliptin, several studies with limitations of pooled analysis showed that linagliptin in patients with T2DM is not associated with an increase in cardiovascular events [35-38]. The results of our study for primary composite outcome (cardiovascular death, non-fatal myocardial infarction and non-fatal ischemic stroke) are compatible with those of previous randomized controlled trials (i.e., SAVOR [12], EXAMINE [13], and TECOS [14] trials), which indicated that shortterm use of DPP-4 inhibitors have a neutral effect on cardiovascular death, myocardial infarction and stroke. Prespecified subgroup analyses in our study suggested that no significant interactions were observed, even in chronic kidney disease (CKD) with or without dialysis. Compared to the results of subgroup analyses in the EXAMINE study which excluded end-stage renal disease (ESRD) patients, the CKD subgroup analyses revealed that alogliptin had an increased primary cardiovascular risk trend in the moderate or severe renal impairment group when compared to the normal or mild renal insufficiency group ( $P$ value for interaction with treatment $=.046)[13]$.

For issues of hospitalization for heart failure, the SAVOR-TIMI 53 study indicated a 27\% increase in hospitalization for heart failure among T2DM patients receiving saxagliptin as compared with those receiving placebo (HR 1.27; 95\% CI 1.07-1.51; $P=.007$ ) [12]. The main predictors of hospitalization for heart failure were previous history of heart failure, elevated brain natriuretic peptide (BNP) and CKD [39]. Compared to patients in the SAVOR study, our patients had more previous history of heart failure (17.5\% in the linagliptin group and $16.1 \%$ in the control group) than did those with previous history 


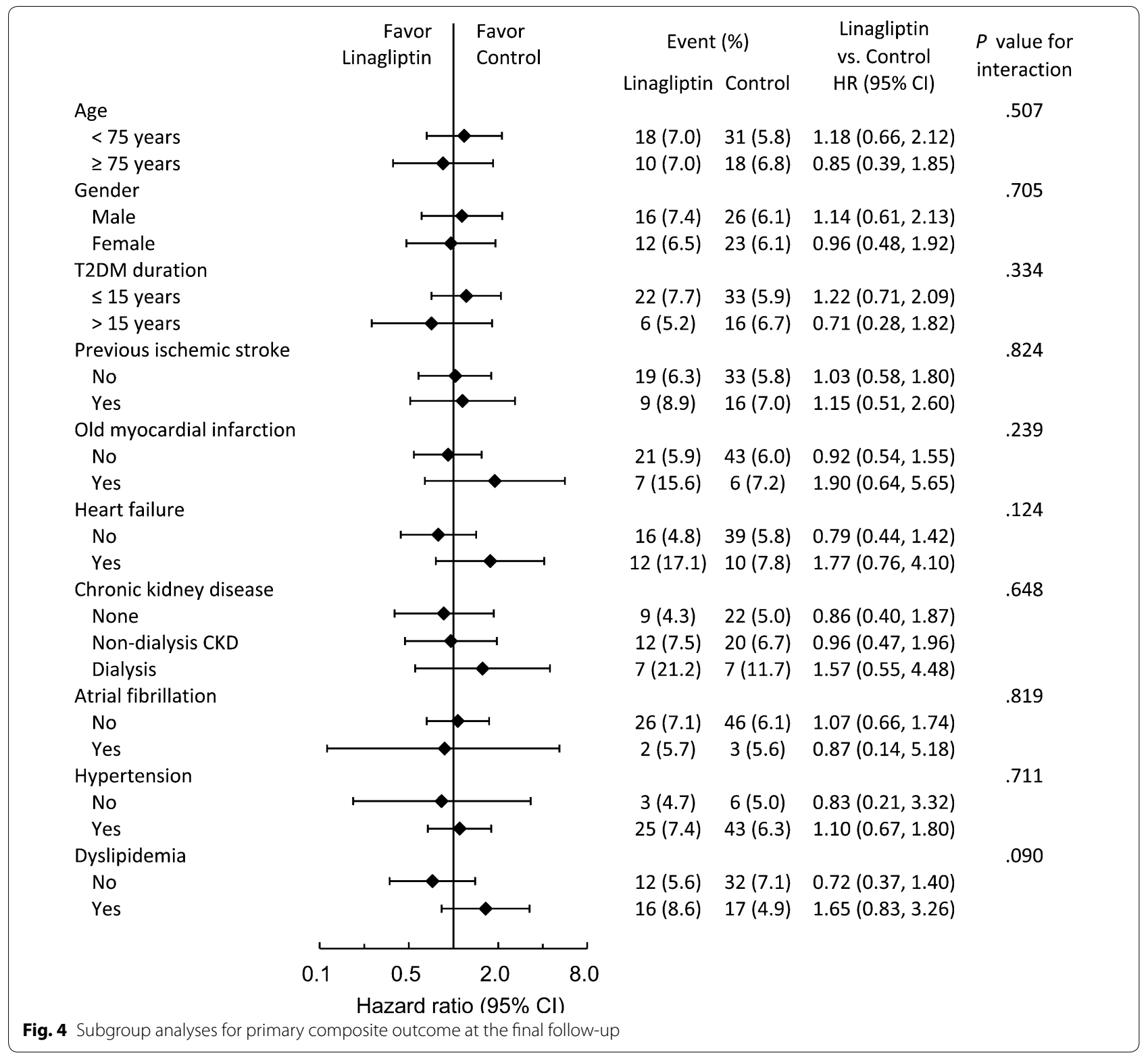

of heart failure in the SAVOR study $(12.8 \%$ in the saxagliptin group and $12.8 \%$ in the placebo group). Besides, unlike the SAVOR study which excluded patients with ESRD receiving long-term dialysis, our study enrolled those with ESRD on dialysis (8.2\% in the linagliptin group and $7.5 \%$ in the control group). As a result, our result showing that linagliptin had a neutral effect on hospitalization for heart failure could be more convincing and supported that it should not be a class effect of all DPP-4 inhibitors in regards to heart failure.

\section{Protective effects of vascular diseases}

In preclinical studies, linagliptin could prevent female mice from western diet-induced vascular abnormalities [40], and even reverse western diet-induced diastolic dysfunction possibly by targeting TRAF3IP2 expression which is associated with downstream inflammatory signaling [41]. DPP-4 inhibitor-medicated increased GLP-1 may have a direct effect at the neuronal level of brain which was suspected to be associated with the neuroprotective effect on the stroke mice [42].

In clinical studies, the initial combination of linagliptin and metformin substantially enhanced glycemic control without weight gain and with infrequent hypoglycemia 
Table 3 Primary and secondary outcomes in T2DM with ACS at the end of follow-up

\begin{tabular}{|c|c|c|c|c|}
\hline \multirow[t]{2}{*}{ Outcome } & \multicolumn{2}{|l|}{ Number of event (\%) } & \multicolumn{2}{|c|}{ Linagliptin vs. control } \\
\hline & Linagliptin $(n=154)$ & $\begin{array}{l}\text { Control } \\
(n=308)\end{array}$ & $\mathrm{HR}(95 \% \mathrm{Cl})$ & $P$ \\
\hline \multicolumn{5}{|l|}{ Primary outcomes } \\
\hline \multicolumn{5}{|l|}{6 month follow-up } \\
\hline Cardiovascular death & $5(3.2)$ & $11(3.6)$ & $.83(.29,2.40)$ & .735 \\
\hline Non-fatal myocardial infarction & $6(3.9)$ & $8(2.6)$ & $1.38(.48,3.99)$ & .547 \\
\hline Non-fatal ischemic stroke & $1(.6)$ & $3(1.0)$ & $.62(.06,5.95)$ & .678 \\
\hline Primary composite outcome ${ }^{a}$ & $10(6.5)$ & $22(7.1)$ & $.84(.40,1.78)$ & .648 \\
\hline \multicolumn{5}{|l|}{ At the end of follow-up } \\
\hline Cardiovascular death & $8(5.2)$ & $13(4.2)$ & $1.13(.47,2.73)$ & .781 \\
\hline Non-fatal myocardial infarction & $7(4.5)$ & $10(3.2)$ & $1.29(.49,3.38)$ & .610 \\
\hline Non-fatal ischemic stroke & $3(1.9)$ & $3(1.0)$ & $1.89(.38,9.34)$ & .438 \\
\hline Primary composite outcome ${ }^{a}$ & $15(9.7)$ & $26(8.4)$ & $1.08(.57,2.03)$ & .821 \\
\hline \multicolumn{5}{|l|}{ Secondary outcomes } \\
\hline All-cause mortality & $13(8.4)$ & $23(7.5)$ & $1.07(.54,2.12)$ & .840 \\
\hline \multicolumn{5}{|l|}{ Other cardiovascular outcomes } \\
\hline Hospitalization for heart failure & $16(10.4)$ & $22(7.1)$ & $1.41(.74,2.69)$ & .292 \\
\hline Percutaneous coronary intervention & $23(14.9)$ & $30(9.7)$ & $1.48(.86,2.54)$ & .160 \\
\hline Coronary artery bypass grafting & $4(2.6)$ & $6(1.9)$ & $1.25(.35,4.44)$ & .727 \\
\hline \multicolumn{5}{|l|}{ Safety outcomes } \\
\hline Hypoglycemia & $6(3.9)$ & $8(2.6)$ & $1.43(.50,4.12)$ & .509 \\
\hline DKA or HHS & $1(.6)$ & $2(.6)$ & $.96(.09,10.54)$ & .970 \\
\hline Acute pancreatitis & $0(.0)$ & $0(.0)$ & NA & NA \\
\hline De novo dialysis & $10(6.5)$ & $16(5.2)$ & $1.31(.59,2.89)$ & .512 \\
\hline Acute hepatitis & $2(1.3)$ & $0(.0)$ & NA & NA \\
\hline Newly diagnosed malignancy & $1(.6)$ & $5(1.6)$ & $.38(.04,3.25)$ & .377 \\
\hline
\end{tabular}

ACS acute coronary syndrome, $C l$ confidence interval, $C V$ cardiovascular, DKA diabetic ketoacidosis, HHS hyperosmolar hyperglycemic state, HR hazard ratio, NA not applicable, T2DM type 2 diabetes mellitus

a Anyone of cardiovascular death, non-fatal myocardial infarctionand non-fatal ischemic stroke

[43] and also significantly improved microvascular function in the fasting state [44]. Besides, the special issues of linagliptin is about neuroprotective effects based on some evidences showing that patients treated with linagliptin were significantly associated with fewer events of stroke $[25,26]$. Patients with diabetes have a twofold excess risks for ischemic stroke compared with those without diabetes [2] and acute stroke could lead to stress hyperglycemia with increased mortality and poor prognosis [45]. Moreover, stroke-mediated damage could increase the permeability of the BBB which may have a influence on DPP-4 inhibitors for neuroprotection [46]. In the present study, we included patients with recent AIS as a part of the study population. Nevertheless, our results did not find a significant anti-stroke effect with linagliptin treatment at the final follow-up. A 2-year, randomized, double-blind, non-inferiority trial including 1,552 patients by Gallwitz et al. indicated that patients treated with linagliptin had significantly fewer non-fatal stroke than those treated with glimepiride ( 3 vs. 11 patients; HR .27;
95\% CI .08-.97; $P=.03$ ) [25]. The actual reason for this discrepancy is unclear. However, any of the following explanations may apply. First, the patients in our study conducted in Taiwan were mostly an Asian population. By comparison, the study by Gallwitz et al. only enrolled $12 \%$ Asian patients. Because intracranial atherosclerosis is relatively common in Asia [47], the clinical influence of linagliptin may be different in Asian subjects compared to Western subjects. Second, the etiology of ischemic stroke is heterogeneous with large vessel disease, small vessel disease, and embolism which may lead to different effects of linagliptin according to the different etiologies. Third, in our study, we enrolled patients with old ischemic stroke (28.1\% in the linagliptin group and $29.5 \%$ in the control group) after recent AIS; in contrast, the study by Gallwitz et al. excluded patients with stroke or transient ischemic attack within 6 months before enrollment [25]. Because of the obvious differences in disease severity of the populations, the overall rate of non-fatal ischemic stroke in our study was $2.4 \%$ at 15 months but 
Table 4 Primary and secondary outcomes in T2DM with AIS at the end of follow-up

\begin{tabular}{|c|c|c|c|c|}
\hline \multirow[t]{2}{*}{ Outcome } & \multicolumn{2}{|l|}{ Number of event (\%) } & \multicolumn{2}{|c|}{ Linagliptin vs. control } \\
\hline & Linagliptin ( $n=239$ ) & Control $(n=478)$ & $\mathrm{HR}(95 \% \mathrm{Cl})$ & $P$ \\
\hline \multicolumn{5}{|l|}{ Primary outcomes } \\
\hline \multicolumn{5}{|l|}{6 month follow-up } \\
\hline Cardiovascular death & $4(1.7)$ & $9(1.9)$ & $.85(.26,2.75)$ & .782 \\
\hline Non-fatal myocardial infarction & $0(.0)$ & $0(.0)$ & NA & NA \\
\hline Non-fatal ischemic stroke & $6(2.5)$ & $24(5.0)$ & $.47(.19,1.14)$ & .095 \\
\hline Primary composite outcome ${ }^{\mathrm{a}}$ & $10(4.2)$ & $33(6.9)$ & $.57(.28,1.15)$ & .114 \\
\hline \multicolumn{5}{|l|}{ At the end of follow-up } \\
\hline Cardiovascular death & $4(1.7)$ & $10(2.1)$ & $.77(.24,2.46)$ & .658 \\
\hline Non-fatal myocardial infarction & $0(.0)$ & $0(.0)$ & NA & NA \\
\hline Non-fatal ischemic stroke & $7(2.9)$ & $27(5.6)$ & $.49(.21,1.12)$ & .089 \\
\hline Primary composite outcome ${ }^{\mathrm{a}}$ & $11(4.6)$ & $36(7.5)$ & $.57(.29,1.12)$ & .104 \\
\hline \multicolumn{5}{|l|}{ Secondary outcomes } \\
\hline All-cause mortality & $9(3.8)$ & $21(4.4)$ & $.88(.40,1.92)$ & .742 \\
\hline \multicolumn{5}{|l|}{ Other cardiovascular outcomes } \\
\hline Hospitalization for heart failure & $4(1.7)$ & $7(1.5)$ & $1.14(.33,3.88)$ & .839 \\
\hline Percutaneous coronary intervention & $3(1.3)$ & $4(.8)$ & $1.45(.32,6.47)$ & .628 \\
\hline Coronary artery bypass grafting & $0(.0)$ & $0(.0)$ & NA & NA \\
\hline \multicolumn{5}{|l|}{ Safety outcomes } \\
\hline Hypoglycemia & $10(4.2)$ & $18(3.8)$ & $1.10(.51,2.38)$ & .811 \\
\hline DKA or HHS & $2(.8)$ & $3(.6)$ & $1.33(.22,7.97)$ & .754 \\
\hline Acute pancreatitis & $0(.0)$ & $0(.0)$ & NA & NA \\
\hline De novo dialysis & $8(3.3)$ & $17(3.6)$ & $1.20(.50,2.86)$ & .679 \\
\hline Acute hepatitis & $0(.0)$ & $1(.2)$ & NA & NA \\
\hline Newly diagnosed malignancy & $7(2.9)$ & $14(2.9)$ & $1.32(.52,3.39)$ & .561 \\
\hline
\end{tabular}

AIS acute ischemic stroke, $C l$ confidence interval, $C V$ cardiovascular, DKA diabetic ketoacidosis, HHS hyperosmolar hyperglycemic state, HR hazard ratio, NA not applicable, T2DM type 2 diabetes mellitus

a Anyone of cardiovascular death, non-fatal myocardial infarctionand non-fatal ischemic stroke

the overall non-fatal stroke rate of the study by Gallwitz et al. was only $.9 \%$ at 2 years.

\section{Study limitations}

The major limitations of our study are as follows. First, personal information of our patients such as smoking, life style, body mass index, family history of cardiovascular disease or laboratory parameters including levels of glycated hemoglobin were not available. Nevertheless, we were able to include a wide range of variables related to outcomes, including comorbidities and non-study medications, to make our two study groups well balanced. Second, we assumed that patients adhered properly to their treatment medications in the claims data. Third, this is an observational trial and causal effect relationship should be carefully interpreted. Furthermore, it remains unclear whether the findings of our study are applicable to other ethnicities because the population in the present study was in Asia and unique. Our study showed higher use of insulin, sulfonylurea, and alpha-glucosidase inhibitors compared with the United States or Europe. The reasons why the high rates of use with alpha-glucosidase inhibitors, sulfonylurea, and insulin could be as follows. Postprandial hyperglycemia is more common in Asians than in Caucasians $[48,49]$ and one possible reason could be people in Asia take more carbohydrates and whole grains such as rice or noodles for their meals [50, 51]. Alphaglucosidase inhibitors which mainly lower postprandial hyperglycemia may have greater effectiveness in Asians than Caucasians and can be a first-line drug according to the guideline of T2DM in China [52-54]. In our present study, we enrolled more patients of CKD with or without dialysis (linagliptin group: $48.4 \%$ and control group: $44.6 \%)$ because linagliptin is no dosage adjustment required in renal insufficiency including ESRD with dialysis which make it more popular in CKD patients. For patients with non-dialysis CKD who estimated glomerular filtration rate $\left(\right.$ eGFR) $>25 \mathrm{ml} / \mathrm{min} / 1.73 \mathrm{~m}^{2}$, alpha-glucosidase inhibitors (such as acarbose), sulfonylurea (such as glipizide) and insulin are alternative drugs 


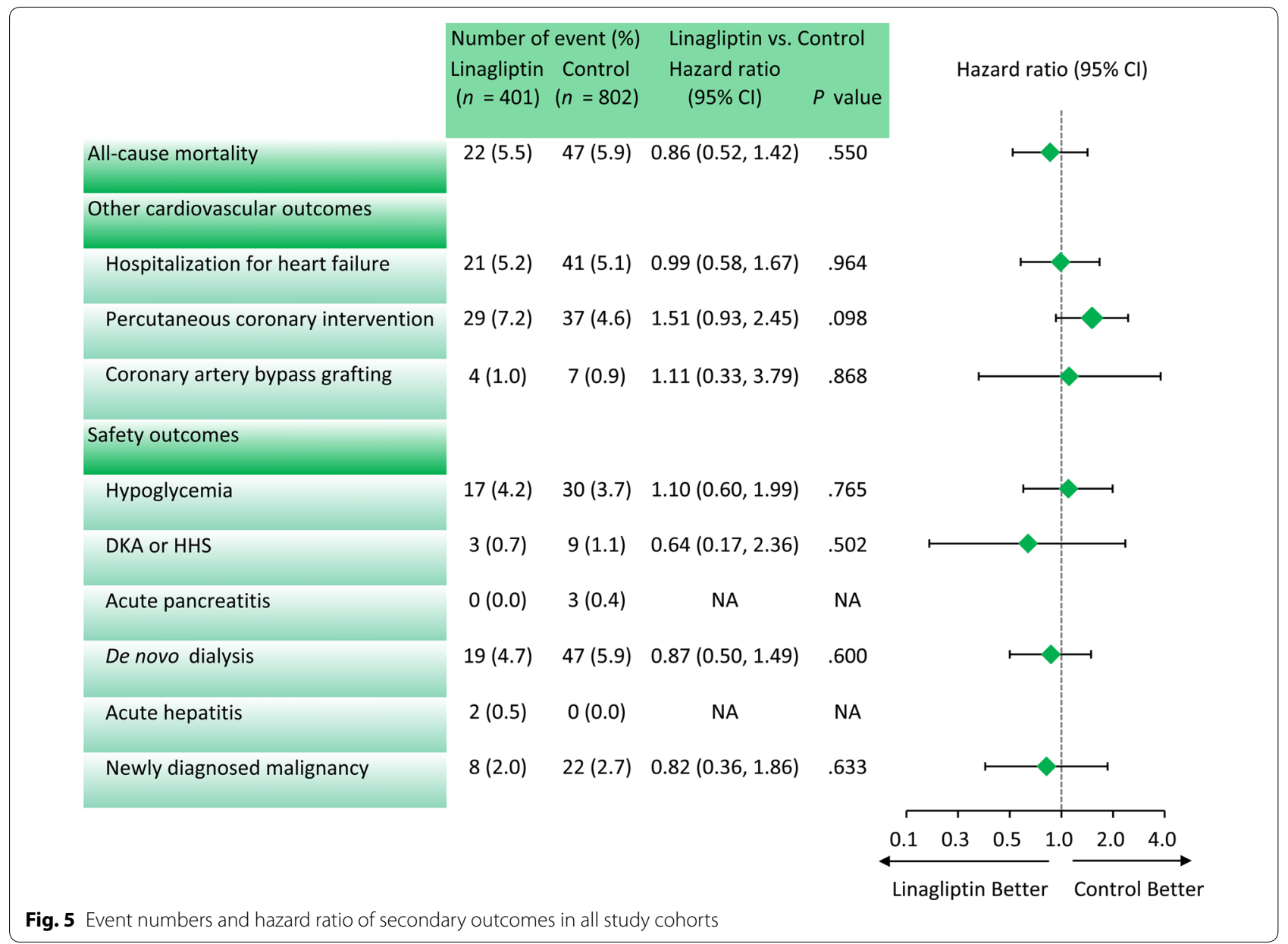

for treatment of T2DM instead of metformin; for patient with dialysis, both sulfonylurea (such as glipizide, still can be used with caution) and insulin could be the main drugs with DPP-IV inhibitors for blood glucose control because other anti-hyperglycemic agents are contraindicated or relatively contraindicated in dialysis patients.

Finally, our study has a mean of 4.7 months and a maximum of 15 months of follow-up because linagliptin was available in Taiwan since 2012. Studies with longer duration of follow-up in the future may provide more information in this special population which is considerably at high cardiovascular risks. Despite these disadvantages, our real-world and nationwide population-based data is still valuable to answer uncertain questions before and after the results of CARMELINA and CAROLINA are published. For these patients at extremely high risks of further cardiovascular events, randomized controlled trials are not always feasible due to considerations of ethical issues, time, or cost.

\section{Conclusions}

In summary, the use of linagliptin in patients with T2DM after ACS or AIS could have a neutral effect on composite cardiovascular events without increasing the risks of all-cause mortality, hospitalization for heart failure, receiving percutaneous coronary intervention, and coronary artery bypass grafting. These results could help clinicians to choose linagliptin as an adequate anti-diabetic agent for T2DM patients at extremely high risks of further cardiovascular events.

\section{Abbreviations}

T2DM: Type 2 diabetes mellitus; ACS: acute coronary syndrome; AIS: acute ischemic stroke; DPP-4: dipeptidyl peptidase-4; GLP-1: glucagon-like peptide-1; CKD: chronic kidney disease; ESRD: end-stage renal disease; $P C I$ : percutaneous coronary intervention; CABG: coronary artery bypass grafting; DKA: diabetic ketoacidosis; HHS: hyperosmolar hyperglycemic state; HR: hazard ratio; Cl: confidence interval.

\section{Authors' contributions}

Authors contributions are as follows: (1) study conception and design (Y-RL, S-ST, T-HC); (2) drafting of the manuscript (Y-RL, S-ST, D-YC); (3) data analysis 
and interpretation (Y-RL, S-ST, D-YC, S-TC, J-HS, H-YC, M-JL, T-HC). All authors read and approved the final manuscript.

\section{Author details}

${ }^{1}$ Division of Endocrinology and Metabolism, Department of Internal Medicine, Chang Gung Memorial Hospital, Taoyuan, Taiwan. ${ }^{2}$ Division of Cardiology, Department of Internal Medicine, Chang Gung Memorial Hospital, Taoyuan, Taiwan. ${ }^{3}$ Division of Cardiology, Department of Internal Medicine, Chang Gung Memorial Hospital, No.222, Maijin Road, Keelung, Taiwan. ${ }^{4}$ Chang Gung University College of Medicine, Taoyuan, Taiwan.

\section{Acknowledgements}

We thank Hsing-Fen Lin and Ya-Jhu Shu for their statistical assistance.

\section{Competing interests}

The authors declare that they have no competing interests.

\section{Availability of data and materials}

The datasets used and analyzed in our study are available from the corresponding author on reasonable requests.

\section{Consent for publication}

Authors give full consents for publication of the present article.

\section{Ethics approval and consent to participate}

The protocol of this study and informed consent of all participants were approved by the Ethics Institutional Review Board of Chang Gung Memorial Hospital (201701079B1).

\section{Funding}

This work was supported by grants from the Chang Gung Memorial Hospital, Taiwan (CGRPG2F0011, CLRPG2C0021, CLRPG2C0022, CLRPG2C0023, CLRPG2C0024, and CLRPG2G0081).

\section{Publisher's Note}

Springer Nature remains neutral with regard to jurisdictional claims in published maps and institutional affiliations.

Received: 10 October 2017 Accepted: 26 December 2017

Published online: 04 January 2018

\section{References}

1. Haffner SM, Lehto S, Rönnemaa T, Pyörälä K, Laakso M. Mortality from coronary heart disease in subjects with type 2 diabetes and in nondiabetic subjects with and without prior myocardial infarction. N Engl J Med. 1998:339:229-34

2. Sarwar N, Gao P, Seshasai SR, Gobin R, Kaptoge S, Di Angelantonio E, et al. Diabetes mellitus, fasting blood glucose concentration, and risk of vascular disease: a collaborative meta-analysis of 102 prospective studies. Lancet. 2010;375:2215-22.

3. Preis SR, Hwang SJ, Coady S, Pencina MJ, D'Agostino RB Sr, Savage PJ, et al. Trends in all-cause and cardiovascular disease mortality among women and men with and without diabetes mellitus in the Framingham Heart Study, 1950 to 2005. Circulation. 2009;119:1728-35.

4. Morrish NJ, Wang SL, Stevens LK, Fuller JH, Keen H. Mortality and causes of death in the WHO Multinational Study of Vascular Disease in Diabetes. Diabetologia. 2001;44(Suppl 2):14-21.

5. UK Prospective Diabetes Study (UKPDS) Group. Intensive blood-glucose control with sulphonylureas or insulin compared with conventional treatment and risk of complications in patients with type 2 diabetes (UKPDS 33). Lancet. 1998;352:837-53.

6. Gerstein HC, Miller ME, Byington RP, Goff DC Jr, Bigger JT, Buse JB, et al Effects of intensive glucose lowering in type 2 diabetes. N Engl J Med. 2008:358:2545-59.

7. Patel A, MacMahon S, Chalmers J, Neal B, Billot L, Woodward M, et al. Intensive blood glucose control and vascular outcomes in patients with type 2 diabetes. N Engl J Med. 2008;358:2560-72.
8. Gerstein HC, Miller ME, Genuth S, Ismail-Beigi F, Buse JB, Goff DC Jr, et al Long-term effects of intensive glucose lowering on cardiovascular outcomes. N Engl J Med. 2011;364:818-28.

9. Wing RR, Bolin P, Brancati FL, Bray GA, Clark JM, Coday M, et al. Cardiovascular effects of intensive lifestyle intervention in type 2 diabetes. $N$ Engl J Med. 2013;369:145-54.

10. Cavender MA, Steg PG, Smith SC, Eagle K, Ohman EM, Goto S, et al. Impact of diabetes mellitus on hospitalization for heart failure, cardiovascular events, and death: outcomes at 4 years from the reduction of atherothrombosis for continued health $(\mathrm{REACH})$ registry. Circulation. 2015:132:923-31.

11. Guidance for industry. diabetes mellitus — evaluating cardiovascular risk in new antidiabetic therapies to treat type 2 diabetes. Silver Spring: Food and Drug Administration; 2008.

12. Scirica BM, Bhatt DL, Braunwald E, Steg PG, Davidson J, Hirshberg B, et al. Saxagliptin and cardiovascular outcomes in patients with type 2 diabetes mellitus. N Engl J Med. 2013;369:1317-26.

13. White WB, Cannon CP, Heller SR, Nissen SE, Bergenstal RM, Bakris GL, et al. Alogliptin after acute coronary syndrome in patients with type 2 diabetes. N Engl J Med. 2013;369:1327-35.

14. Green JB, Bethel MA, Armstrong PW, Buse JB, Engel SS, Garg J, et al. Effect of sitagliptin on cardiovascular outcomes in type 2 diabetes. N Engl J Med. 2015;373:232-42.

15. Zannad F, Cannon CP, Cushman WC, Bakris GL, Menon V, Perez AT, et al. Heart failure and mortality outcomes in patients with type 2 diabetes taking alogliptin versus placebo in EXAMINE: a multicentre, randomised, double-blind trial. Lancet. 2015;385:2067-76.

16. FDA Drug Safety Communication: FDA adds warnings about heart failure risk to labels of type 2 diabetes medicines containing saxagliptin and alogliptin. https://www.fda.gov/Drugs/DrugSafety/ucm486096.htm. Accessed 5 Apr 2016

17. Filion KB, Suissa S. DPP-4 inhibitors and heart failure: some reassurance, some uncertainty. Diabetes Care. 2016:39:735-7.

18. Baetta R, Corsini A. Pharmacology of dipeptidyl peptidase-4 inhibitors: similarities and differences. Drugs. 2011;71:1441-67.

19. Deacon CF, Holst JJ. Linagliptin, a xanthine-based dipeptidyl peptidase-4 inhibitor with an unusual profile for the treatment of type 2 diabetes. Expert Opin Investig Drugs. 2010;19:133-40.

20. Graefe-Mody U, Friedrich C, Port A, Ring A, Retlich S, Heise T, et al. Effect of renal impairment on the pharmacokinetics of the dipeptidyl peptidase-4 inhibitor linagliptin. Diabetes Obes Metab. 2011;13:939-46.

21. Boehringer Ingelheim. Cardiovascular and Renal Microvascular Outcome Study With Linagliptin in Patients With Type 2 Diabetes Mellitus (CARMELINA). [ClinicalTrials.gov identifier: NCT01897532]. US National Institutes of Health, ClinicalTrials.gov. https:/clinicaltrials.gov/ct2/show/NCT01897532 Accessed 2017 Oct 4.

22. Boehringer ingelheim. CAROLINA: Cardiovascular Outcome Study of Linagliptin Versus Glimepiride in Patients With Type 2 Diabetes. [ClinicalTrials. gov identifier: NCT01243424]. US National Institutes of Health, ClinicalTrials.gov. https://clinicaltrials.gov/ct2/show/NCT01243424 Accessed 2017 Oct 4.

23. McKeage K. Linagliptin: an update of its use in patients with type 2 diabetes mellitus. Drugs. 2014;74:1927-46.

24. Barnett $\mathrm{AH}$. Linagliptin for the treatment of type 2 diabetes mellitus: a drug safety evaluation. Expert Opin Drug Saf. 2015;14:149-59.

25. Gallwitz B, Rosenstock J, Rauch T, Bhattacharya S, Patel S, von Eynatten M, et al. 2-year efficacy and safety of linagliptin compared with glimepiride in patients with type 2 diabetes inadequately controlled on metformin: a randomised, double-blind, non-inferiority trial. Lancet. 2012;380:475-83.

26. Johansen OE, Neubacher D, von Eynatten M, Patel S, Woerle HJ. Cardiovascular safety with linagliptin in patients with type 2 diabetes mellitus: a pre-specified, prospective, and adjudicated meta-analysis of a phase 3 programme. Cardiovasc Diabetol. 2012;11:3.

27. Hsieh CY, Chen CH, Li CY, Lai ML. Validating the diagnosis of acute ischemic stroke in a National Health Insurance claims database. J Formos Med Assoc. 2015;114:254-9.

28. Chang CH, Lee YC, Tsai CT, Chang SN, Chung YH, Lin MS, et al. Continuation of statin therapy and a decreased risk of atrial fibrillation/flutter in patients with and without chronic kidney disease. Atherosclerosis. 2014:232:224-30. 
29. Cheng CL, Lee CH, Chen PS, Li YH, Lin SJ, Yang YH. Validation of acute myocardial infarction cases in the national health insurance research database in taiwan. J Epidemiol. 2014;24:500-7.

30. Cheng CL, Kao YH, Lin SJ, Lee CH, Lai ML. Validation of the National Health Insurance Research Database with ischemic stroke cases in Taiwan. Pharmacoepidemiol Drug Saf. 2011;20:236-42.

31. Hsing AW, loannidis JP. Nationwide population science: lessons from the Taiwan National Health Insurance Research Database. JAMA Intern Med. 2015;175:1527-9.

32. Wu CY, Chen YJ, Ho HJ, Hsu YC, Kuo KN, Wu MS, et al. Association between nucleoside analogues and risk of hepatitis B virus-related hepatocellular carcinoma recurrence following liver resection. JAMA. 2012;308:1906-14.

33. Ou HT, Chang KC, Li CY, Wu JS. Risks of cardiovascular diseases associated with dipeptidyl peptidase-4 inhibitors and other antidiabetic drugs in patients with type 2 diabetes: a nation-wide longitudinal study. Cardiovasc Diabetol. 2016;15:41.

34. Kim YG, Yoon D, Park S, Han SJ, Kim DJ, Lee KW, et al. Dipeptidyl peptidase-4 inhibitors and risk of heart failure in patients with Type 2 diabetes mellitus: a Population-Based Cohort Study. Circ Heart Fail. 2017;10(9):e003957.

35. Lehrke M, Leiter LA, Hehnke U, Thiemann S, Bhandari A, Meinicke T, et al. Safety and efficacy of linagliptin in patients with type 2 diabetes mellitus and coronary artery disease: analysis of pooled events from 19 clinical trials. J Diabetes Complications. 2016;30:1378-84.

36. Zinman B, Ahren B, Neubacher D, Patel S, Woerle HJ, Johansen OE. Efficacy and cardiovascular safety of linagliptin as an add-on to insulin in Type 2 diabetes: a Pooled Comprehensive Post Hoc Analysis. Can J Diabetes. 2016:40:50-7.

37. Rosenstock J, Marx N, Neubacher D, Seck T, Patel S, Woerle HJ, et al. Cardiovascular safety of linagliptin in type 2 diabetes: a comprehensive patient-level pooled analysis of prospectively adjudicated cardiovascular events. Cardiovasc Diabetol. 2015;14:57.

38. Lehrke M, Marx N, Patel S, Seck T, Crowe S, Cheng K, et al. Safety and tolerability of linagliptin in patients with Type 2 diabetes: a Comprehensive Pooled Analysis of 22 Placebo-controlled Studies. Clin Ther. 2014;36:1130-46.

39. Scirica BM, Braunwald E, Raz I, Cavender MA, Morrow DA, Jarolim P, et al. Heart failure, saxagliptin, and diabetes mellitus: observations from the SAVOR-TIMI 53 randomized trial. Circulation. 2014;130:1579-88.

40. Manrique C, Habibi J, Aroor AR, Sowers JR, Jia G, Hayden MR, et al. Dipeptidyl peptidase-4 inhibition with linagliptin prevents western diet-induced vascular abnormalities in female mice. Cardiovasc Diabetol. 2016;15:94.

41. Aroor AR, Habibi J, Kandikattu HK, Garro-Kacher M, Barron B, Chen D, et al. Dipeptidyl peptidase-4 (DPP-4) inhibition with linagliptin reduces western diet-induced myocardial TRAF3IP2 expression, inflammation and fibrosis in female mice. Cardiovasc Diabetol. 2017;16:61.
42. Darsalia V, Ortsater H, Olverling A, Darlöf E, Wolbert P, Nyström T, et al. The DPP-4 inhibitor linagliptin counteracts stroke in the normal and diabetic mouse brain: a comparison with glimepiride. Diabetes. 2013;62:1289-96.

43. Ma RC, Del Prato S, Gallwitz B, Shivane VK, Lewis-D'Agostino D, Bailes Z, et al. Oral glucose lowering with linagliptin and metformin compared with linagliptin alone as initial treatment in Asian patients with newly diagnosed type 2 diabetes and marked hyperglycemia: subgroup analysis of a randomized clinical trial. J Diabetes Investig. 2017. https://doi. org/10.1111/jdi.12746.

44. Jax T, Stirban A, Terjung A, Esmaeili H, Berk A, Thiemann S, et al. A randomised, active- and placebo-controlled, three-period crossover trial to investigate short-term effects of the dipeptidyl peptidase-4 inhibitor linagliptin on macro- and microvascular endothelial function in type 2 diabetes. Cardiovasc Diabetol. 2017;16:13

45. Capes SE, Hunt D, Malmberg K, Pathak P, Gerstein HC. Stress hyperglycemia and prognosis of stroke in nondiabetic and diabetic patients: a systematic overview. Stroke. 2001;32:2426-32.

46. Darsalia V, Nathanson D, Nystrom T, Klein T, Sjoholm A, Patrone C. GLP-1R activation for the treatment of stroke: updating and future perspectives. Rev Endocr Metab Disord. 2013:62:1289-96.

47. Holmstedt CA, Turan TN, Chimowitz MI. Atherosclerotic intracranial arterial stenosis: risk factors, diagnosis, and treatment. Lancet Neurol. 2013;12:1106-14

48. International DE, DECODA Study Group. Cardiovascular risk profile assessment in glucose-intolerant Asian individuals - an evaluation of the World Health Organization two-step strategy: the DECODA Study (Diabetes Epidemiology: Collaborative Analysis of Diagnostic Criteria in Asia). Diabet Med. 2002;19:549-57.

49. DECODE Study Group, European Diabetes Epidemiology Study Group. Will new diagnostic criteria for diabetes mellitus change phenotype of patients with diabetes? Reanalysis of European epidemiological data. DECODE Study Group on behalf of the European Diabetes Epidemiology Study Group. BMJ. 1998;317:371-5.

50. Ma RC. Acarbose: an alternative to metformin for first-line treatment in type 2 diabetes? Lancet Diabetes Endocrinol. 2014;2:6-7.

51. Zhu Q, Tong Y, Wu T, Li J, Tong N. Comparison of the hypoglycemic effect of acarbose monotherapy in patients with type 2 diabetes mellitus consuming an Eastern or Western diet: a systematic meta-analysis. Clin Ther. 2013;35:880-99.

52. Chiasson JL, Josse RG, Gomis R, Hanefeld M, Karasik A, Laakso M. Acarbose for prevention of type 2 diabetes mellitus: the STOP-NIDDM randomised trial. Lancet. 2002;359:2072-7.

53. Weng J, Soegondo S, Schnell O, Sheu WH, Grzeszczak W, Watada H, et al. Efficacy of acarbose in different geographical regions of the world: analysis of a real-life database. Diabetes Metab Res Rev. 2015;31:155-67.

54. Weng J, Ji L, Jia W, Lu J, Zhou Z, Zou D, et al. Standards of care for type 2 diabetes in China. Diabetes Metab Res Rev. 2016;32:442-58.

\section{Submit your next manuscript to BioMed Central and we will help you at every step:}

- We accept pre-submission inquiries

- Our selector tool helps you to find the most relevant journal

- We provide round the clock customer support

- Convenient online submission

- Thorough peer review

- Inclusion in PubMed and all major indexing services

- Maximum visibility for your research

Submit your manuscript at www.biomedcentral.com/submit
BioMed Central 